\title{
ANALYSIS OF THE CONSTRUCTION AND OPERATION OF THE CASCADE REFRIGERATION
}

\author{
Krasimir Ivanov, Nely Georgieva \\ Trakia University, Faculty of Technics and Technologies, \\ Graf Ignatiev 38, 8602 Yambol, Bulgaria, \\ e-mail: krasimirivanov1978@abv.bg
}

\begin{abstract}
The contemporary industry places requirements to them for achieving temperatures lower than $-100^{\circ} \mathrm{C}$, for example in the liquefaction of gases; liquefaction of air, followed by separation of its components (nitrogen, oxygen, argon, neon, helium, xenon); usage of cryogenic temperatures in medicine. Obtain such low temperatures is associated with a number of problems associated with increase of energy consumption, with the construction of the refrigeration machine such as a minimum possible pressure of the suction compressor which can practically ensure. The report provides an analysis of the working principle of cascading refrigeration and used refrigerants, according to updates of the existing legislation. Study for conducted researches on getting low temperatures by using cascaded machines and combinations of various refrigerants is made.
\end{abstract}

Keywords: refrigerants, freons, cascading refrigeration.

\section{INTRODUCTION}

The purpose of the refrigeration machines is to conduct heat from the cooling equipment at a temperature lower than the ambient temperature. Their operation is based on the withdrawal of heat from the cooled body, which, at the expense of spending of mechanical, thermal or other type of energy is transmitted to the cooling environment.

The industrial refrigeration machines are among the most common and universal sources of cold, which can ensure production of cold in the range of a few hundred watts to several megawatts.

The contemporary industry places requirements to them for achieving temperatures lower than $-100^{\circ} \mathrm{C}$, for example in the liquefaction of gases; liquefaction of air, followed by separation of its components (nitrogen, oxygen, argon, neon, helium, xenon); usage of cryogenic temperatures in medicine. Obtain such low temperatures is associated with a number of problems associated with increase of energy consumption, with the construction of the refrigeration machine such as a minimum possible pressure of the suction compressor which can practically ensure.

On the other hand, in order imposed in recent years, environmental requirements to use refrigerants, opportunities for obtaining low temperatures by traditional single-stage refrigeration are limited seriously.

These are the reasons that make cascading machines more attractive. In the scientific literature of recent years can be found a number of studies for optimization of their design and selection of appropriate refrigerants, which proves the relevance of the problem.

In the present article was made literary study of the current status and achievements in the field of research for obtaining relatively low temperatures by using a cascade machines and various combinations of refrigerants. 


\section{IRTIIE \\ Ipplied Reseirrches in Technics, Technologies and Bducition \\ Journal of the Faculty of Technics and Technologies, Trakia University https://sites.google.com/a/trakia-uni.bg/artte/}

\section{ANALYSIS OF REFRIGERANT USED FOR ASSURANCE OF LOW TEMPERATURES FOR COOLING}

Various requirements are brought to the refrigerants- thermodynamic, physico-chemical, physiological, economic and environmental.

The most direct impact on the possibility of obtaining low cooling temperatures has thermodynamic properties of refrigerants.

To relieve the construction of the compressor and increasing its mechanical efficiency condensing pressure $p_{\mathrm{k}}$ refrigerant should be low. To prevent suction of the outside air in the installation the pressure boiling $p_{o}$ must be higher or close to it. The ratio between $p_{\kappa}$ and $p_{o}$ should be as little as possible.

In piston compressors it has a decisive influence on the working coefficients and determines the temperature of the vapor after the process of compression, which must not exceed $130^{\circ} \mathrm{C}$ for refrigeration compressors.

Also the ratio $p_{k} / p_{o}$ determines the number of steps in compression refrigeration machine. The specific mass and volume production of cold should be great. The critical temperature should be high to reduce the irreversible loss of throttling.

The freezing point of the refrigerant should be low. The specific heat capacity, the kinematic viscosity of the refrigerant and the metric value of adiabatic $\mathbf{k}$ should be small.

The heat of evaporation should be large because the cold production and the amount of refrigerant that circulates in the system depend from it.

When analyzing the thermodynamic properties of refrigerants is established that all known fluids used as refrigerants, have certain drawbacks, which more or less make them unsuitable for obtaining very low temperatures.

According equilibrium curves refrigerants are divided into three groups (Table 1):

- Refrigerants of the first group - refrigerants with low pressure condensation $R_{C}<0,2$ $0,3 \mathrm{MPa}$ and high normal boiling point $\mathrm{T}_{\mathrm{N}}>0^{\circ} \mathrm{C}$;

- refrigerants in the second group - medium pressure refrigerants condensation $R_{C}<1,5$ $2 \mathrm{MPa}$ and average normal boiling temperature $\mathrm{T}_{\mathrm{N}}<0^{\circ} \mathrm{C}$;

- refrigerants from a third group - refrigerants high pressure condensation $R_{C}>2 M P a$ and low normal boiling temperature $\mathrm{T}_{\mathrm{N}}<-50^{\circ} \mathrm{C}$.

From presented data in Table 1 is seen that when is need low temperatures for cooling are suitable refrigerants from a third group, but they require the provision of high pressure for the process of condensation, which places increased demands on the construction of the refrigeration machine.

In connection with the directives of the European Union (№2037 / 200) refrigerants from the group of HCFC (R-21, R-123) are appeared as temporary solution. In directives №2038 / 2000; 2039/2000; 1804/2003 there is a schedule for the ban and the use of CFCs from this group.

Table 1. Normal boiling temperature $t_{N}$ for some refrigerants at an atmospheric pressure $101320 \mathrm{~Pa}$

\begin{tabular}{|c|c|c|c|c|c|c|c|c|c|c|c|}
\hline & \multicolumn{3}{|c|}{ Group onet $t_{N}>0^{\circ} \mathrm{C}$} & \multicolumn{4}{|c|}{ Group twot ${ }_{N}<0^{\circ} \mathrm{C}$} & \multicolumn{4}{|c|}{ Group threet ${ }_{\mathrm{N}}<-50^{\circ} \mathrm{C}$} \\
\hline & R-600 & $\mathrm{R}-21$ & $\mathrm{R}-123$ & $\mathrm{R}-600 \mathrm{a}$ & R-404A & R-134a & R407 & R-23 & $\mathrm{R}-32$ & R-744 & $\mathrm{R}-170$ \\
\hline $\mathrm{tN},{ }^{\circ} \mathrm{C}$ & 0 & 9 & 27 & -12 & -12 & -26 & -39 & -72 & -128 & -78 & -89 \\
\hline
\end{tabular}

Recently, are used a series of new refrigerants which are azeotropic and zeotropic. Azeotropic mixtures are characterized that in the boiling process does not alter their composition. They have equality boiling and condensation points (R-410a, Freon 23). In [11, 13] have been conducted studies on the received parameters using an azeotropic mixture, wherein proven their efficiency.

IRTIIE Vol. 5, No. 1, 2017 ISSN 1314-8788 (print), ISSN 1314-8796 (online), doi: 10.15547/artte.2017.01.005 


\section{IRITIE}

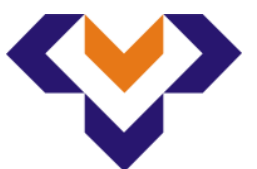

Ipplied Resseirl'hes in Technics, Technologies and Eductition Journal of the Faculty of Technics and Technologies, Trakia University https://sites.google.com/a/trakia-uni.bg/artte/

Zeotropic in the process of boiling change its composition as a result of this, the temperature at which boiling begins for a given pressure is not equal to that of condensation. The difference between these temperatures is called the temperature glide (R-407A; R-405A).

In [7] simulation was performed to determine the parameters of the system in handling natural hydrocarbons and zeotropic.

There are a number of studies $[4,6,7,10,15]$ which offer solutions for use as a refrigerant of carbon dioxide, ammonia, propane, etc., which in the aspect of the introduction of eco-taxes from 1 January 2015 using traditional refrigerants R-404A and R-507, are current. Although they are having a certain potential, there are certain difficulties because they are toxic and explosivedangerous.

\section{PRINCIPLE OF OPERATION AND CAPABILITY OF THE CASCADE MACHINES TO ENSURE THE LOW TEMPERATURES FOR COOLING}

The above disadvantages can be avoided by using cascaded refrigeration machines, which in each circular process in the cascade use different working substances (two or more). A cascade refrigeration machine represent a system of separately operating refrigerating machines, which are connected consecutively and each of them contains four basic components: a compressor, condenser, expansion valve and evaporator.

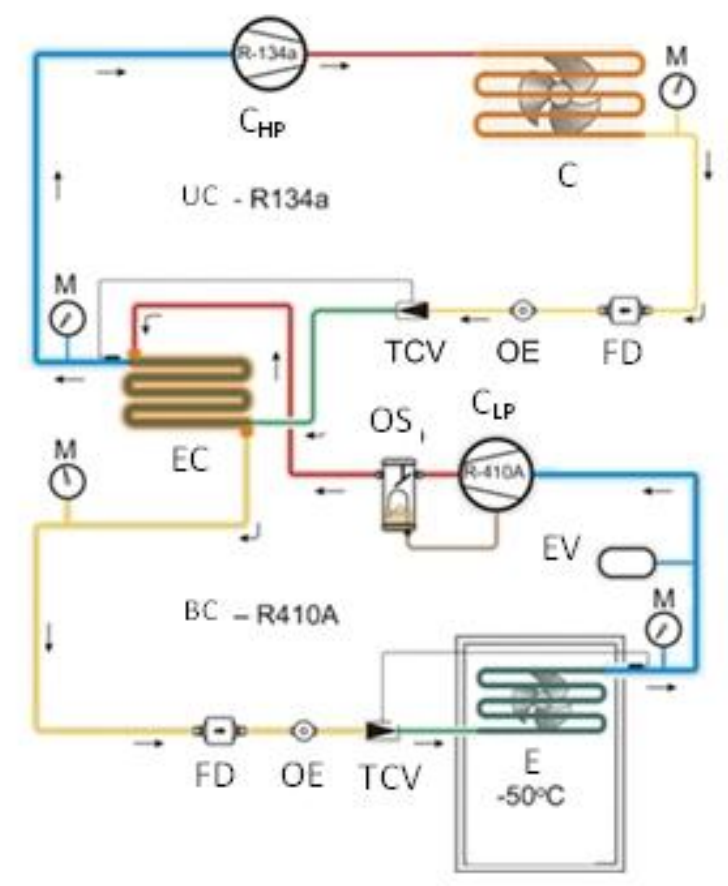

Figure 1. Functional diagram of cascade refrigeration machine:

UC - upper cascade; $\mathrm{BC}$ - bottom cascade; $\mathrm{C}_{\mathrm{HP}}$ - compressor for high pressure; $\mathrm{C}$ condenser; E - evaporator; OE - observation eye; TCV - thermo-control valve; FD - filterdehydrator; $\mathrm{EC}$ - evaporator-condenser; $\mathrm{C}_{\mathrm{LP}}$ - compressor low pressure; $\mathrm{OS}$ - oil separator; EV - expansion vessel; $\mathrm{M}$ - manometer

Figure 1 is a functional diagram of a cascade refrigeration machine.

In the evaporator $(\mathrm{E})$ of the bottom cascade $(\mathrm{BC})$ a refrigerant boils at low temperature and takes heat from the environment. The vapors from the evaporator $(E)$ are sucked from the

IRTIIE Vol. 5, No. 1, 2017 ISSN 1314-8788 (print), ISSN 1314-8796 (online), doi: 10.15547/artte.2017.01.005 


\section{IR'TIE \\ Ipplied Reseirrches in Technics, Technologies and Bducition \\ Journal of the Faculty of Technics and Technologies, Trakia University https:///ites.google.com/a/trakia-uni.bg/artte/}

compressor $\left(\mathrm{C}_{\mathrm{LP}}\right)$, they are compressed adiabatic as their temperature and pressure are raised and they are entered the evaporator-condenser (EC), that combines the evaporator of the upper cascade and condenser of the bottom cascade in a common heat exchanger. The vapors received in the evaporator-condenser condense at the expense of the boiling (evaporation) of the refrigerant on the upper cascade. Between the boiling temperature of the refrigerant of the upper cascade ( $T_{\text {ouc }}$ ) and the temperature of condensation of the bottom cascade $\left(T_{C B C}\right)$ should have a certain temperature difference $\Delta t \geq 5^{\circ} \mathrm{C}$ (Figure 5 ). $T_{C B C}$ of the bottom cascade is higher than the upper cascade $T_{0 u c}$. Already liquefied refrigerant from the bottom cascade enters in the expansion valve (TCV), where is throttled and enters the evaporator at relatively much lower temperature. In the upper cascade (UC) is also carried out single-cycle refrigeration machine, but at a much higher temperature range. In the evaporator of this cascade refrigerant boils and takes away a heat from the refrigerant of the bottom cascade, which condenses. The cascade refrigeration machines have a high ratio of cooling because of the possibility of using various refrigerants in different machines with different values critical temperatures. Typically, in the upper cascade are used refrigerants from the second group (R-404A; R-422D; R-134a; R-407A), and in the bottom cascade refrigerants from a third group (R-13; R-23; R-14 ; R-50; R-508B; R-170) [2,9,13]. Figure 3 depicts a circular process of cascade refrigeration machine in lg $p-h$ diagram in which on the upper step is used R-134a, and of the bottom R-23.

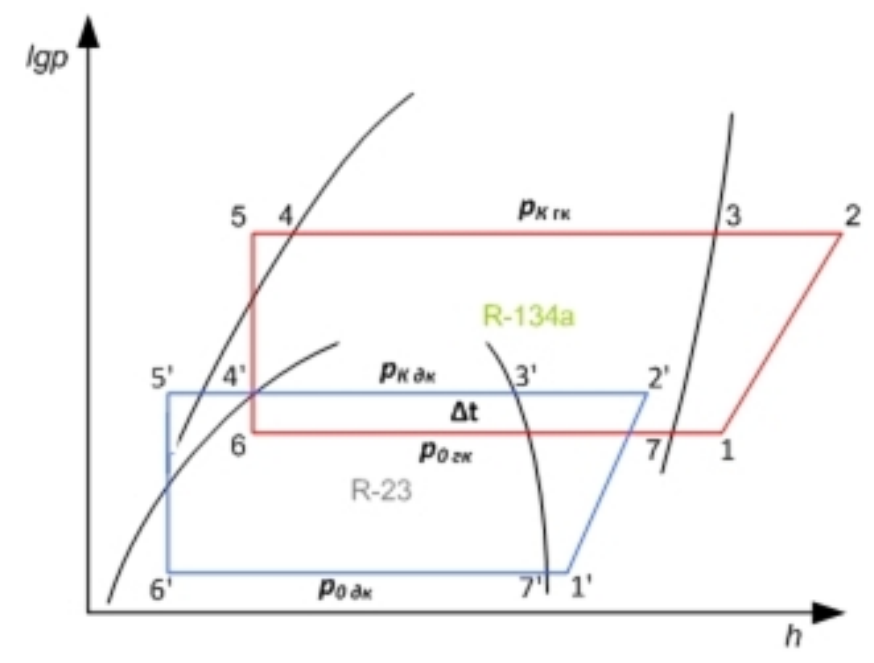

Figure 2. Circular process of a cascade refrigeration machine

In view of the fact that the received temperature of cooling is directly dependent on the pressure drop from the figure 3 is seen that when use of two refrigeration machines operating in a cascade and two refrigerants, for example R-23 и R-134a, it is possible to provide a pressure fall from item 5 to item 6'. The calculations are performed separately for each step of the machine and each circular process in the same way as single-stage or twostage refrigeration. Cold generation in the evaporator of the upper cascade must be equal to the heat which is removed from the condenser of the bottom cascade plus the influx of heat from outside.

A characteristic feature of cascade refrigeration machine is that when it does not work, the pressure in the lower cascade can be increased much. In order to protect the bottom cascade of the high pressure it is necessary to include an expansion tank to the suction side, which when suspended installation to absorb the increase in pressure to a value for which

IRTTIE Vol. 5, No. 1, 2017 ISSN 1314-8788 (print), ISSN 1314-8796 (online), doi: 10.15547/artte.2017.01.005 


\section{IRTIIE

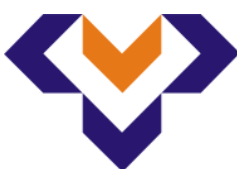 \\ Ipplied Resseirlores in Technics, Technologies and Educration \\ Journal of the Faculty of Technics and Technologies, Trakia University \\ https:///ites.google.com/a/trakia-uni.bg/artte/}

the elements of the machine are calculated. Another solution is the upper cascade to work permanently.

Depending on the temperature conditions of the working process in the upper circular cascade can be carried out with two-stage compression, and at the bottom with a single stage. To obtain the temperatures lower than $-110^{\circ} \mathrm{C}$ in both cascades two-stage compression is used, which complicates the scheme and affects the coefficient of performance COP. It is an important parameter for determining the efficiency of refrigeration machines and is ratio of cold-productivity to the consumed electric power $(\mathrm{kW} / \mathrm{kW})$ installation.

\section{ANALYSIS OF SCHEMES OF CASCADE MACHINES}

There are combinations of cascade refrigeration machines with variety steps and energy used for refrigeration, compression ratio and number of circular processes.

On the basis of made literary study in Figure 3 is presents the classification of a combination of refrigeration machines in cascade depending upon the energy used refrigeration machines, the number of circular process, the number of steps compounded from conducted an overview study.

In [8] is presented experimental design of two-stage cascade machine that used a refrigerant $\mathrm{R}-134 \mathrm{a}$. It was found that the change of the flow of water that is used in the second step has no significant effect on the coefficient of performance COP of the individual steps of the system. The coefficient of performance COP is mainly a function of the evaporation temperature and pressure. A significant drawback of the proposed solution is increased power consumption.

In [1] is an experiment for the operation of single-stage and two-stage refrigeration machines using refrigerants $\mathrm{NH}_{3}$ and $\mathrm{CO}_{2}$ is implemented. As a result, it was found that the two-stage machines have higher $\mathrm{COP}$ as at temperatures below $-40^{\circ} \mathrm{C}$ more good indicators are obtained by combined use of $\mathrm{NH}_{3}$ and $\mathrm{CO}_{2}$.

In [5] is presented steam absorption refrigeration system with refrigerants $\mathrm{LiBr}-\mathrm{H}_{2} \mathrm{O}$ to obtain temperatures below $-40^{\circ} \mathrm{C}$, whose work has been compared with the two-stage steam engine. Taking into account the operating temperature and the heat was reported that the installation maintains high value of $\mathrm{COP}$ in a wide range of operating conditions.

In practice there are auto-cascade installations which are systems with a single compressor and two refrigerants with different condensation temperature and reflux, through which can be prepared cold. The main disadvantage of these systems is the separation of pure refrigerants during the working cycle. In [3] has been conducted a theoretical study of cycles of operation of auto-cascade machine using refrigerant - zeotropic mixture, which could be used as a basis for the design and analysis of such systems.

In [14] has studied the use of ejector in auto-cascade refrigeration machine for creating a theoretical computer model used R-23/R-134a. As a result, it is found that it is possible to improve the efficiency of the cycle of cooling and increasing the COP.

Figure 4 shows the often used cascade refrigeration machine with two evaporatorcondensers as in the bottom cascade is turned regenerative heat exchanger RHE, designed for sub-cooling the liquid refrigerant using cold vapors which coming from the evaporator [8, 12]. Thus, it is possible to reduce the losses from throttling and to improve working coefficients of the compressor. 


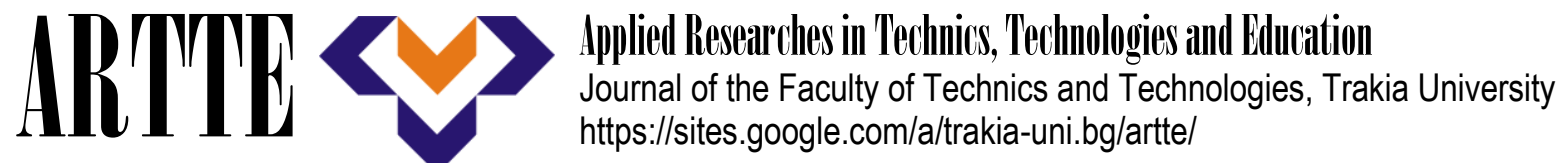

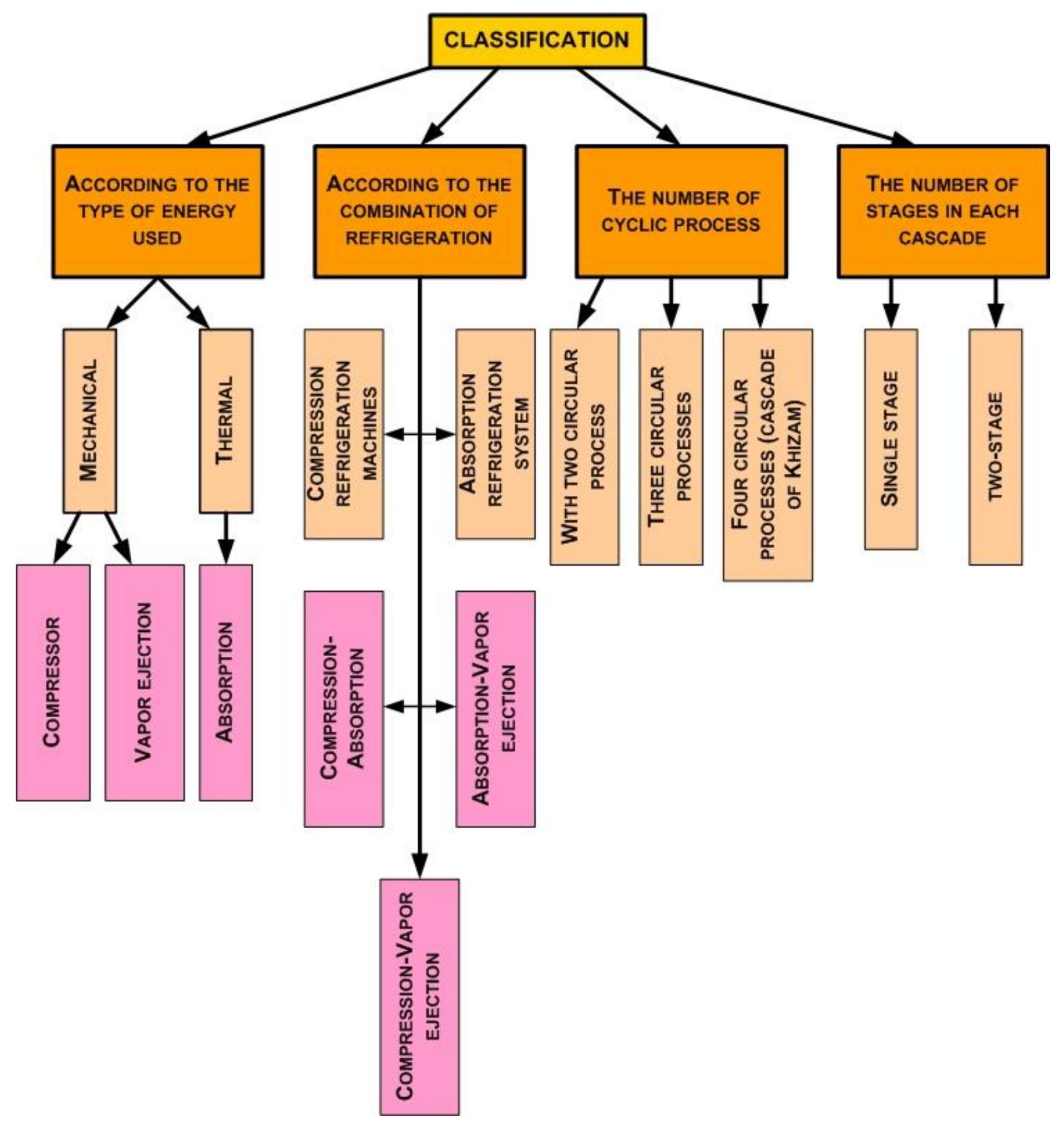

Figure 3.

Classification of the combination of refrigeration machines in cascade 


\section{ARTTIE $Y$}

Ipplied Reseirrches in Technics, Technologies and Bducition Journal of the Faculty of Technics and Technologies, Trakia University https://sites.google.com/a/trakia-uni.bg/artte/

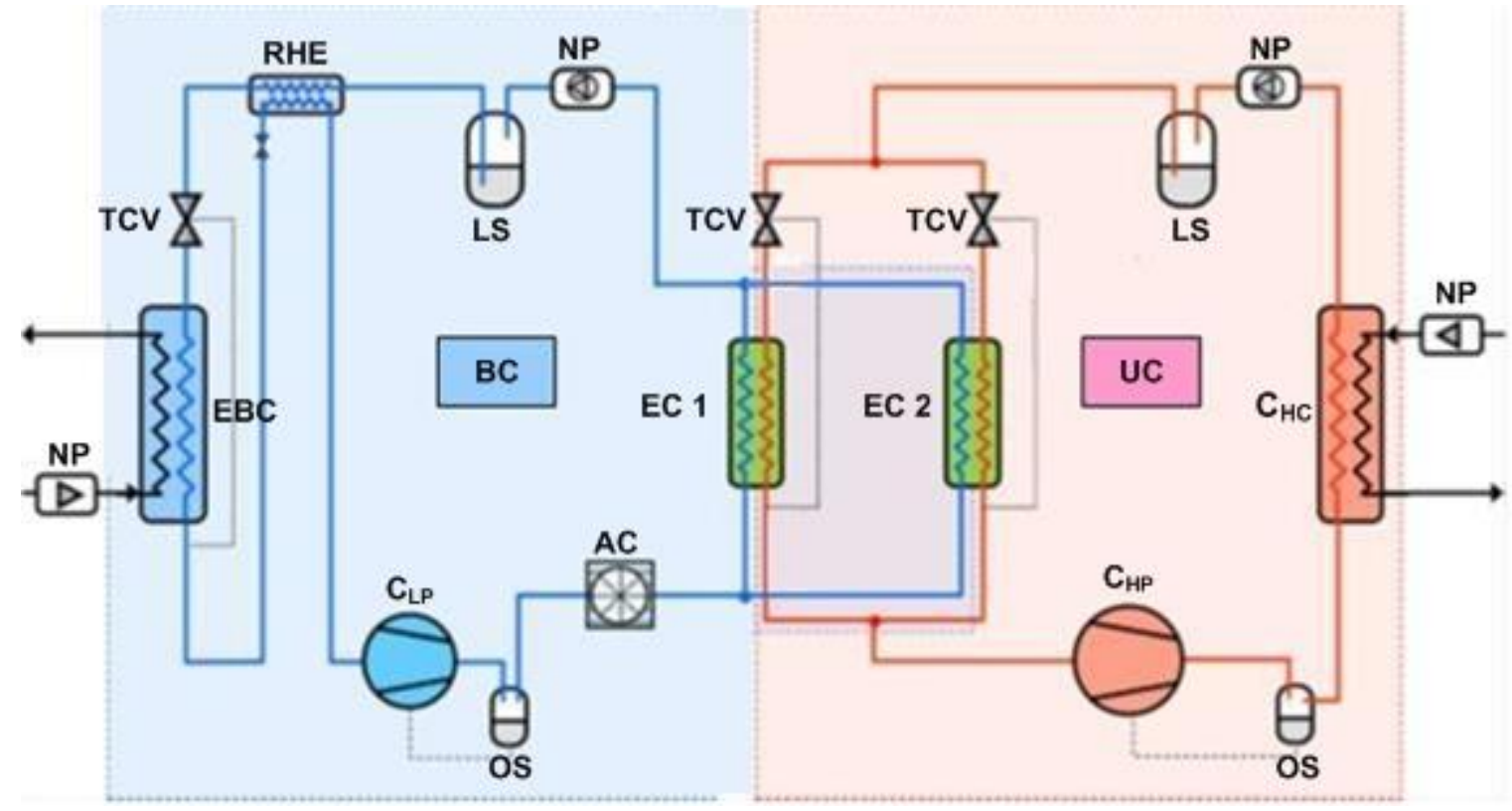

Figure 4. Cascade refrigeration machine with two evaporator-condenser and regenerative heat exchanger (subcooler)

RHE- regenerative heat exchanger; TCV- thermo-control valve; EBC- evaporator in bottom cascade; BC- bottom cascade; LS- liquid separator; AC- air cooler; NP- network pump; $\mathrm{C}_{\mathrm{LP}^{-}}$ compressor low pressure; EC 1, EC 2- evaporator-condenser; UC- upper cascade; $\mathrm{C}_{\mathrm{HC}^{-}}$ condenser for higher cascade; OS - oil separator

As a result, it is reduced vapor content after control valve TCV, thereby increasing the specific production of cold, although it is not justified by particular values. Specifically received performance in operation of this circuit depends on the combination of refrigerants that will be used.

\section{CONCLUSION}

From conducted literature research, part of which has been presented into this report it should be formulated following conclusions:

- There is activity in research of optimizing the structure of cascading systems to obtain higher coefficient of performance - COP;

- The experimental results for the selection of appropriate refrigerants that meet the new requirements in the regulatory framework are provided in a number of scientific studies;

- It was not found the existence of a systematic study of achievements in the development of cascading installations, a prerequisite for the expansion of this study;

- Proposed is a classification of surveyed cascade machines, which will be supplemented in subsequent studies.

\section{ACKNOWLEDGEMENTS}

The work presented in this paper is partially supported by grand of faculty of "Technics and technologies", 5.FTT/ 30.04.2015: "Analysis of energy efficiency of buildings"

IRTIIE Vol. 5, No. 1, 2017 ISSN 1314-8788 (print), ISSN 1314-8796 (online), doi: 10.15547/artte.2017.01.005 


\section{ARTTIE $Y$}

Ipplied Resseirlores in Technics, Technologies and Educration

Journal of the Faculty of Technics and Technologies, Trakia University https://sites.google.com/a/trakia-uni.bg/artte/

\section{REFERENCES}

[1] Bingming W., W.Huagen, L. Jianfeng, X.Ziwen. Experimental investigation on the performance of $\mathrm{NH} 3 / \mathrm{CO} 2$ cascade refrigeration system with twin-screw compressor, International Journal of Refrigeration, ISSN: 0140-7007, Vol: 32, Issue: 6, Page: 13581365, 2009.

[2] Dichev S., Refrigeration machines, Technika, Sofia, 1987.

[3] Du Kai, Shaoqian Zhang, Weirong Xu, XiaofengNiu. A study on the cycle characteristics of an auto-cascade refrigeration system, Experimental Thermal and Fluid Science Volume 33, Issue 2, January 2009, Pages 240-245.

[4] Fikiin A., Basics of refrigeration machines and technologies, Technika, Sofia, 1981.

[5] Garimella S., Ashlie M. Brown, Ananda Krishna Nagavarapu. Waste heat driven absorption/vapor-compression cascade refrigeration system for megawatt scale, highflux, low-temperature cooling, International Journal of Refrigeration, Volume 34, Issue 8, December 2011, Pages 1776-1785.

[6] Georgiev R., K. Peichev, A. Pavlov, K. Trendafilov, G. Dineva, I. Binev, Study of a zeolite-water experimental refrigeration module intended for animal raising, Agricultural science and technology, vol.5, No1 , 2013, ISSN 1313-8820, pp.58-61.

[7] Hadgipetrov E., T. Gachilov, T. Todorov, Ts. Tsolov, N. Komarov, M. Ivanov, Handbook of refrigeration technics, Technika, Sofia, 1970.

[8] Kilicarslan A., An experimental investigation of a different type vapor compression cascade refrigeration system, Applied Thermal Engineering 24 (2004) 2611-2626.

[9] Ladin N. V., Basics of refrigeration machines theory, 2007.

[10] Llopis R., C. Sanz-Kock, R. Cabello, D. Sánchez, L. Nebot-Andrés, J. Catalán-Gil, Effects caused by the internal heat exchanger at the low temperature cycle in a cascade refrigeration plant, Applied Thermal Engineering, vol.103, 2016, pp.1077-1086.

[11] Nachev N., Thermodinamical properties of ecology compatible refrigerans, Sofia, 2010.

[12] SaidaFedali, Hakim Madani, CherifBougriou. Modeling of the thermodynamic properties of the mixtures:Prediction of the position of azeotropes for binary mixtures, Fluid Phase Equilibria, Volume 379, 15 October 2014, Pages 120-127.

[13] Yanxing Zhao, Maoqiong Gong, Xueqiang Dong, Haiyang Zhang, HaoGuo, Jianfeng Wu. Prediction of ternary azeotropic refrigerants with a simple method, Fluid Phase Equilibria, Volume 425, 15 October 2016, Pages 72-83.

[14] Yu J., Hua Zhao, Yanzhong Li. Application of an ejector in autocascade refrigeration cycle for the performance improvement, Volume 31, Issue 2, Pages 279-286 (March 2008).

[15] Zlatev Z., Modeling of color changes in bread crust during baking. ICTTE International Conference on Technics, Technologies and Education, Faculty of Technics and Technologies, Trakia University, October 30-31, 2014, pp.680-685, ISSN 1314-9474. 